\title{
GABA in Hepatic Proliferation and Regeneration
}

\author{
Wang $\mathrm{S}^{1}$, Zhang $\mathrm{L}^{2}$, Liu $\mathrm{C}^{1}$ and Lu $\mathrm{W}^{3 *}$ \\ ${ }^{1}$ Department of Physiology and Pathophysiology, Shandong University School of Basic \\ Medicine, China \\ ${ }^{2}$ Department of Peripheral Vascular Diseases, University of Traditional Chinese \\ Medicine, China
}

${ }^{3}$ Departmentof Physiology and Pharmacology, Robarts Research Institute, University of Western Ontario, Canada

*Corresponding author: Wei-Yang Lu, Departmentof Physiology and Pharmacology, Robarts Research Institute, University of Western Ontario, Richmond St. N, London, ON, N6A 5B7, Canada, Tel: 519-931-5777 ex 24282; Email: wlu53@uwo.ca

\begin{abstract}
Gamma-amino butyric acid (GABA) is a ubiquitous four-carbon, non-protein amino with diverse physiological actions in various types of cells throughout the body. Studies, including ours, show that type A GABA receptor (GABA $\mathrm{R})$-mediated auto- and/or paracrine GABAergic signaling exists in rodent liver, protecting the liver against toxic injuries. This short article briefly introduces the hepatic GABA signaling system and discusses the potential mechanism underlying GABA regulation of cell proliferation and regeneration in the liver.
\end{abstract}

Keywords: GABA receptor; Hepatic proliferation; Hyperpolarization; Cholangiocytosis

Abbreviations: GABA: Gamma-Aminobutyric Acid; CNS: Central Nervous System; GAD: Glutamic and Decarboxylase

\section{Introduction}

It has long been known that $\gamma$-amino butyric acid (GABA) is the primary inhibitory neurotransmitter in the adult central nervous system (CNS) [1]. Functioning as a signal transmitter, GABA generates biological actions in cells through its ionotropic type-A or metabotropic type-B receptors $\left(\mathrm{GABA}_{A} \mathrm{Rs}\right.$ or $\left.\mathrm{GABA}_{B} \mathrm{Rs}\right)$. GABA $\mathrm{G}_{\mathrm{A}} \mathrm{Rs}$ are pentameric channels permeable to chloride ions. To date, totally 19 subunits ( $\alpha 1-6, \beta 1-3, \gamma 1-3, \delta, \varepsilon, \pi, \theta$, and $\rho 1-3$ ) of $\mathrm{GABA}_{\mathrm{A}} \mathrm{R}$ have been cloned in different mammalian cells [2]. For a specific type of mammalian cells only certain subunits are expressed, and $\mathrm{GABA}_{\mathrm{A}} \mathrm{Rs}$ composed of different subunits exhibit diverse physiological and pharmacological properties. Due to the disparity in expression levels of chloride-intruding and chlorideextruding transporters, the intracellular chloride concentrationdiffers among cell types. Therefore, activation of $\mathrm{GABA}_{\mathrm{A}} \mathrm{R}$-channels either causes chlorideinflux (membrane hyperpolarization) or results inchlorideefflux (membrane depolarization), differently regulating the calcium entry hence the function of a specific type of cells.

Studies in the last two decades revealed that GABA is produced by various non-neuronal cells of visceral organs, such as pancreatic endocrine $\beta$-cells, epithelial cells in the intestine, the airway and the intrahepatic biliary duct, and 
immune cells as well [3-9]. In these non-neuronal cells, GABA is formed by a pathway referred to as the GABA shunt, a closed-loop metabolic process occurring in mitochondria with the dual purpose of producing and conserving the supply of GABA [10]. The first step in the GABA shunt is the transamination of $\alpha$-ketoglutarate formed from glucose metabolism through the tricarboxylic acid cycle, by GABA $/ \alpha$-oxoglutarate transaminase, into L-glutamic acid. The latter is catalyzed into GABA by decarboxylation via the enzymatic activity of glutamic acid decarboxylase (GAD), of which two isoforms (GAD65 and GAD67) have been identified.

Early studies hinted a GABAergic signaling in the liver. In 1987, Minuk and colleagues described a bicucullinesensitive $G_{A B A_{A} R}$ signaling in the liver, and this group proposed that alterations in hepatic GABAergic activity may contribute to hepatic regeneration and the pathogenesis of hepatocellular carcinoma [11-13]. Later, another group reported that $\mathrm{GABA}_{A} \mathrm{R}$-mediated signaling also exists in the intrahepatic biliary epithelium, where GABA may stimulate small cholangiocyte differentiation into large cholangiocytes $[14,15]$. However, the precise role of this GABAergic system in hepatocyte regeneration and cholangiocyte proliferation and differentiation remains unclear.

Our recent studies indicate that a $\mathrm{GABA}_{\mathrm{A}} \mathrm{R}$ mediated auto- and/or paracrine signaling system exist in rodent hepatocytes and cholangiocytes as evidenced by the expressions of both the GABA synthesizing enzyme GAD and various $\mathrm{GABA}_{\mathrm{A}} \mathrm{R}$ subunits [7]. Interestingly, pretreating the animals with GABA or the selective $\mathrm{GABA}_{\mathrm{A}} \mathrm{R}$ agonist muscimol, but not the $\mathrm{GABA}_{\mathrm{B}} \mathrm{R}$ agonist baclofen, protected hepatocytes from apoptotic injuries induced by acute and excessive exposure to Dgalactosamine (GalN) or ethanol and hence maintained the integrity of liver function $[7,16]$. Moreover, our study revealed a $\mathrm{GABA}_{A} \mathrm{R}$-mediated signaling mechanism in intrahepatic cholangiocytes of the GalN-induced pseudobile ductules and islet-like structures within the portal and periportal areas of the rodent liver [7]. Remarkably, treating the animal with muscimol fundamentally inhibited the pseudo-duct formation. Our results are in agreement with a previous study showing that a $\mathrm{GABA}_{\mathrm{A}} \mathrm{R}$ mediated autocrine signaling in embryonic stem cells inhibits the cells' proliferation but promote their differentiation [17]. Considering that these proliferating cholangiocytes (also known as oval cells) in rodent livers may contribute to liver regeneration, we propose that $\mathrm{GABA}_{\mathrm{A}} \mathrm{R}$ signaling in the liver may play a role in phenotypic differentiation of oval cells hence regulating liver regeneration [18].
How does the GABA signaling regulate cell proliferation and phenotypic differentiation/transformation? Anovel study recently published in Cell journal shows that longterm treatment with GABA causes a transformation of pancreatic glucagon-producing $\alpha$-cells into a large population of insulin-producing $\beta$-like cells in mice [19]. Given that the small population of $\alpha$-cells in normal pancreatic islets can't account for the genesis of so many $\beta$-like cells in the GABA-treated mice, it is proposed that the GABA-induced neogenesis of $\alpha$-to- $\beta$ cells originates from the exocrine duct epithelium [20]. In this regard, a more recent study in the Lu laboratory also revealed that treating the type 1 diabetic mice with GABA restricts pancreatic $\beta$-cell dedifferentiation but facilitates $\alpha$-to- $\beta$ cell transformation [21]. These combined data suggest that the $\mathrm{GABA}_{\mathrm{A}} \mathrm{R}$-mediated signaling facilitates differentiation of stem cells (or progenitor cells) and confines dedifferentiation of mature cells. It has been proposed that the hepatocytic progenitor cells (oval cells), whose proliferation underlies "ductular reaction" in pathological conditions of the liver, are derived from epithelial cells of the canals of Hering in the periportal region $[18,22,23]$. Therefore, the role of hepatic GABA signaling in phenotypic transformation of epithelial cells at the canals of Hering during liver regeneration should be studied in the future.

\section{References}

1. Olsen RW, Tobin AJ (1990) Molecular biology of GABAA receptors. FASEB J 4(5): 1469-1480.

2. Watanabe M, Maemura K, Kanbara K, Tamayama T, Hayasaki H (2002) GABA and GABA receptors in the central nervous system and other organs. Int Rev Cytol 213: 1-47.

3. Erdo SL (1986) KB in GABAergic Mechanisms in the Mammalian Periphery (Eds.), SL Erdo, et al. Raven Press. pp: 5-17

4. Dong H, Kumar M, Zhang Y, Gyulkhandanyan A, Xiang YY, et al. (2006) Gamma-aminobutyric acid up- and downregulates insulin secretion from beta cells in concert with changes in glucose concentration. Diabetologia 49(4): 697-705.

5. Li Y, Xiang YY, Lu WY, Liu C, Li J (2012) A novel role of intestine epithelial GABAergic signaling in regulating intestinal fluid secretion. Am J Physiol Gastrointest Liver Physiol 303(4): G453-460.

6. Xiang YY, Wang S, Liu M, Hirota JA, Li J, et al. (2007) A GABAergic system in airway epithelium is essential 


\section{Advances in Clinical Toxicology}

for mucus overproduction in asthma. Nat Med 13(7): 862-867.

7. Wang S, Xiang YY, Zhu J, Yi F, Li J, et al. (2017) Protective roles of hepatic GABA signaling in acute liver injury of rats. Am J Physiol Gastrointest Liver Physiol 312(3): G208-G218.

8. Tian J, Dang H, Nguyen AV, Chen Z, Kaufman DL (2014) Combined therapy with GABA and proinsulin/alum acts synergistically to restore longterm normoglycemia by modulating T-cell autoimmunity and promoting beta-cell replication in newly diabetic NOD mice. Diabetes 63(9): 3128-3134.

9. Soltani N, Qiu H, Aleksic M, Glinka Y, Zhao F, et al. (2011) GABA exerts protective and regenerative effects on islet beta cells and reverses diabetes. Proc Nati Acad Sci USA 108(28): 11692-11697.

10. Michaeli S, Fromm H (2015) Closing the loop on the GABA shunt in plants: are GABA metabolism and signaling entwined? Front plant sci 9(6): 419.

11. Minuk GY, Bear CE, Sarjeant EJ (1987) Sodiumindependent, bicuculline-sensitive [3H] GABA binding to isolated rat hepatocytes. Am J Physiol 252(5): G642-647.

12. Minuk GY, Gauthier T (1993) The effect of gammaaminobutyric acid on hepatic regenerative activity following partial hepatectomy in rats. Gastroenterology 104(1): 217-221.

13. Minuk G (2000) GABA and hepatocellular carcinoma. Mol Cell Biochem 207(1-2): 105-108.

14. Mancinelli R, Franchitto A, Gaudio E, Onori P, Glaser S, et al. (2010) After damage of large bile ducts by gamma-aminobutyric acid, small ducts replenishes the biliary tree by amplification of calcium-dependent signaling and de novo acquisition of large cholangiocyte phenotypes. Am J Pathol 176(4): 17901800 .
15. Mancinelli R, Franchitto A, Glaser S, Meng F, Onori P, et al. (2013) GABA induces the differentiation of small into large cholangiocytes by activation of $\mathrm{Ca}(2+)$ /CaMK I-dependent adenylyl cyclase 8. Hepatology 58(1): 251-263.

16. Wang S, Sui S, Liu Z, Peng C, Liu J, et al. (2018) Protective roles of hepatic gamma-aminobutyric acid signaling in acute ethanol exposure-induced liver injury. J Appl Toxicol 38(3): 341-350.

17. Andang M, Hjerling-Leffler J, Moliner A, Lundgren TK, Castelo-Branco G, et al. (2008) Histone H2AXdependent GABA (A) receptor regulation of stem cell proliferation. Nature 451(7177): 460-464.

18. Paku S, Schnur J, Nagy P, Thorgeirsson SS (2001) Origin and structural evolution of the early proliferating oval cells in rat liver. Am J pathol 158(4): 1313-1323.

19. Ben-Othman N, Vieira A, Courtney M, Record F, Gjernes E, et al. (2017) Long-Term GABA Administration Induces Alpha Cell-Mediated Beta-like Cell Neogenesis. Cell 168(1-2): 73-85 e11.

20. Weir GC, Bonner Weir S (2017) GABA Signaling Stimulates beta Cell Regeneration in Diabetic Mice. Cell 168(1-2): 7-9.

21. Feng AL, Xiang YY, Gui L, Kaltsidis G, Feng $Q$ et al. (2017) Paracrine GABA and insulin regulate pancreatic alpha cell proliferation in a mouse model of type 1 diabetes. Diabetologia 60(6): 1033-1042.

22. Alvaro D, Mancino MG, Glaser S, Gaudio E, Marzioni M, et al. (2007) Proliferating cholangiocytes: a neuroendocrine compartment in the diseased liver. Gastroenterology 132(1): 415-431.

23. Lemire JM, Shiojiri N, Fausto N (1991) Oval cell proliferation and the origin of small hepatocytes in liver injury induced by D-galactosamine. Am J pathol 139(3): 535-552. 